\title{
Problemas Hermenêuticos em um Texto Técnico Antigo: o De architectura de Vitrúvio
}

\author{
Júlio César Vitorino
}

\begin{abstract}
Resumo
Este trabalho apresenta algumas considerações sobre o estado atual da recepção do De architectura de Vitrúvio, caracterizado por sérias divergências entre os estudiosos, as quais, geralmente, transcendem as dificuldades lingüísticas e podem ser explicadas pelo desenvolvimento do processo hermenêutico ao longo dos séculos em que a obra tem sido estudada.
\end{abstract}

Palavras-chave: Vitrúvio. De architectura. Recepção. Leitura.

O léxico de Vitrúvio constitui um conjunto de palavras muito peculiar. De um total de aproximadamente cinco mil palavras, bem mais da metade são termos técnicos, a maioria dos quais conhecidos somente através do autor ou atestados apenas em sua obra no sentido por ele utilizado. Isso vale também para as palavras gregas, ou de origem grega, que constituem aproximadamente dez por cento do total, o que permite afirmar que o autor é importantíssimo para o conhecimento de uma parte conspícua do vocabulário grego e latino. Esse fato meritório nos coloca um grande problema: como ler, como compreender o texto de Vitrúvio?

Um texto técnico como o De architectura reduz bastante a liberdade do intérprete, mas não a elimina totalmente. O sentido de um hápax, por exemplo, geralmente é uma questão problemática, pois o seu significado, sugerido pelas afinidades etimológicas, só se esclarece no contexto. Quando o sentido geral depende do significado da palavra obscura toda a compreensão fica prejudicada. Nesse ponto, cabe ao intérprete encontrar um sentido que concilie as duas exigências, ou seja, a formação da palavra e o significado no passo em que se apresenta. Outras vezes, o significado de uma palavra comum não dá sentido à leitura e se presume tratar-se de uma corrupção; nesse momento, a crítica textual deve ser acionada para corrigir a forma transmitida, substituindo-a por outra que justifique a transformação ocorrida.

Em linha geral, deve-se defender as lições transmitidas, sempre que ofereçam algum sentido possível, respeitando a regra da lectio difficilior. No âmbito da tradição hermenêutica, entretanto, essa prática, mesmo se programaticamente respeitada, é abandonada com muita freqüência, prevalecendo quase sempre o sentido esperado. Há mesmo uma certa tendência em polir demais o texto vitruviano, que acaba perdendo algumas das suas características essenciais. A inadequação da tradição manuscrita do De architectura em relação às metodologias lachmanianas e pós-lachmanianas abre 
espaço para um amplo recurso ao iudicium. E, realmente, esse recurso se impõe quase como uma necessidade, diante da exigência de compreensão que, no caso de um tratado técnico, é muito amplificada. Tampouco, no caso de Vitrúvio, o recurso à "tradição" (em sentido gadameriano; cf. GADAMER, 1960) é uma opção segura, pois, como pode ser observado, muitas vezes não há possibilidade de consenso entre as diversas "tradições". O intérprete então é forçado a fazer uma opção entre as diversas interpretações e, caso nenhuma lhe seja satisfatória, é obrigado a propor uma nova, o que complica ainda mais o estado do "horizonte hermenêutico". Em geral, o amplo debate em torno de cada questão tem levado a um deslocamento desse horizonte sempre em sentido da nova proposição, desde que esta seja fruto de uma revisão crítica das anteriores e que provenha de uma reconhecida auctoritas. Nesse sentido, pode-se falar em uma limitação à liberdade do intérprete, mas, em muitos casos, mesmo em publicações importantes, o texto de Vitrúvio é interpretado de forma absolutamente arbitrária (cf., por exemplo, ALARÇÃO, 1978). Esses casos, porém, são facilmente reconhecíveis pela pouca perícia dos autores em lidar com o material lingüístico do autor.

Em geral, os estudiosos estabelecem inúmeras analogias entre a teoria da arquitetura exposta por Vitrúvio e a retórica. É quase um lugar-comum se afirmar que Vitrúvio utiliza largamente a nomenclatura do sistema retórico transferindo os seus vocábulos, com alterações de significado mais ou menos discretas, para o campo da arquitetura. A amplitude dessa afirmação deve ser redimensionada, pois é possível demonstrar que os termos comuns à retórica utilizados por Vitrúvio não são tantos e são geralmente polissêmicos, possuindo, além do significado técnico, um significado comum que na maioria das vezes é o principal. De outro modo, a sua teoria seria uma espécie de paródia da teoria retórica, contrariando a seriedade buscada na exposição. Em outros casos, a proximidade formal das palavras sugere uma proximidade da organização dos conceitos. Existe, porém, uma distinção de fundo entre as duas artes. O pressuposto da retórica, enquanto ars, ou seja, enquanto conhecimento que pode ser transmitido, é a inuentio. Esse conceito é retomado por Vitrúvio, que a ele acrescenta a necessidade da cogitatio. Desse modo, a sua arquitetura não é a simples aplicação de formas já existentes na memória a um caso específico. Cada novo caso exige a ação do raciocínio e apenas o raciocínio pode ter como resultado "coisas novas": nesse ponto, a arquitetura atinge o estatuto de verdadeira ciência. O "templo dórico perfeito" de Vitrúvio, por exemplo, é geralmente considerado análogo aos exercícios típicos das escolas de retórica. Realmente, para um problema praticamente insolúvel, como o conflito do tríglifo angular, o arquiteto tenta encontrar uma solução. A natureza do problema exige uma solução nova, ainda não codificada em um repertório. Dessa forma, o problema exige a intervenção do poder do raciocínio e, por isso, a solução apresentada está muito mais próxima da solução sóbria de um problema matemático que de uma genial tirada retórica. De qualquer forma, deve-se reconhecer que, no âmbito da cultura latina, é a retórica, inspirada pela filosofia, a disciplina que fornece o vocabulário e as questões de uma estética geral (MICHEL, 1973 , p. 302-305). A presença de termos e conceitos oriundos da retórica na teoria arquitetônica de Vitrúvio não deve, portanto, ser atribuída a uma atitude peculiar do autor, é antes um fato da cultura antiga na qual a crítica literária, apoiada pela disciplina retórica, tinha inúmeros pontos de contato com a crítica de arte.

Também a formação vitruviana do arquiteto costuma ser comparada aos modelos de formação do orador presentes nos manuais de retórica, mas, na verdade, é melhor relacionar a idéia de uma encyclios disciplina, como reunião de diversas disciplinas, 
com o modelo para a formação do cidadão, do homem livre, que restringi-la ao âmbito da retórica. Assim, a sua adoção em âmbito arquitetônico corrobora a reivindicação vitruviana de se conferir à arquitetura o caráter de arte liberal. É com essa intenção que ele se dirige ao Princeps, dedicando-lhe a obra, pois acredita que, para o incremento da maiestas imperii, a arquitetura tenha uma função importante, que ele se dirige aos sapientes, pois o conhecimento da arquitetura é necessário para o conhecimento do mundo e da civilização; que ele se dirige ao pater familias, que deve entender de arquitetura para melhor gestão das suas obras de construção. Além disso, Vitrúvio contempla também o caráter profissional da atividade do arquiteto. A sua teoria está voltada para o estabelecimento de um sistema de valores para a atuação em um âmbito profissional cada vez mais ocupado por incompetentes gananciosos. A constatação dessa realidade, que ele denuncia, exige um programa de valorização da profissão, concretizado na obra através da definição rigorosa de uma verdadeira ética profissional (GROS, 1994, p. 86-87).

A questão da auto-declaração de uma limitada formação literária não deve ser utilizada absolutamente para uma crítica negativa do tratado de Vitrúvio. Através deste topos literário o autor consegue demonstrar a necessidade da construção de uma linguagem técnica, diversa, peculiar à sua disciplina - o que constitui, sem dúvida, uma das suas principais realizações. O projeto de construção de uma terminologia isenta de equívocos pode não ter sido levado a termo completamente, mas, nas entrelinhas, instaura-se um processo de afirmação da arquitetura enquanto discurso formalizado, o que justifica a reivindicação de valorização intelectual e social dessa disciplina.

A inclusão da arquitetura no rol das artes liberais, a despeito do seu caráter parcialmente manual, se justifica por sua componente mental, por ser uma arte que é prática, mas também teoria. A ciência enciclopédica de Vitrúvio só pode ser perfeitamente compreendida se for dado o devido valor à sua reivindicação de que a arquitetura é ciência. Constata-se, na obra, que é muito mais forte a influência da sistematização das ciências naturais que a do sistema retórico. As suas definições e classificações se baseiam principalmente na subdivisão de gêneros e na individuação das espécies no interior de um gênero. A típica divisão da matéria tratada de acordo com os quatro elementos, presente nos tratados de história natural, deixou traços profundos na obra. A própria arquitetura é insistentemente conclamada a transcender os tradicionais requisitos da firmitas, utilitas e uenustas, e aderir a uma função de natureza sanitária. Partindo da interpretação da natureza da matéria, o arquiteto tem condições de controlar os agentes climáticos e ambientais nocivos à saúde do homem, através da assimilação dos princípios climáticos e topográficos aos quatro elementos que compõem a matéria.

Os interesses de Vitrúvio, no entanto, superam os limites da sua disciplina, e é por amor às palavras que ele realiza o ambicioso projeto de sistematizar a rosa-dosventos mais completa de toda a Antigüidade. O excursus da rosa-dos-ventos não é absolutamente funcional à discussão da sua teoria urbanística, na qual se insere a digressão. O seu projeto de organizar esse amplo campo semântico ilustra bem a direção "nominativa" presente na obra. Ele parte das palavras, quase como realidades ontológicas, para, a partir daí, definir a coisa. Se existem nomes e os nomes são diversos, existem coisas diversas às quais os nomes se referem. $O$ mesmo pode ser dito em relação aos elementos arquitetônicos.

Nas definições das tipologias de templos, por exemplo, o autor segue determinada série de nomes, e uma tipologia que não corresponda a essa série não 
tem lugar no seu esquema, sendo mencionada, quando o é, em seções distintas. Assim, ao descrever a série in antis, prostylos, amphiprostylos, peripteros, pseudodipteros, dipteros, não há lugar para as aedes rotundae, pois ele tem em mente apenas templos retangulares. Será apenas por desejo de ser completo que ele dedica uma seção à parte aos templos redondos, apresentando então uma nova série, monopteros e peripteros, que irá entrar em conflito com a definição do peripteros da série anterior.

O templo redondo de Vitrúvio é um bom exemplo de uma interpretação do texto que se mantém graças à força da tradição. A partir de uma relação métrica provavelmente equivocada, mas de qualquer modo já presente no arquétipo, perpetuou-se uma leitura que, no meu entender, não corresponde à idéia original. Atualmente é opinião quase unânime a interpretação do períptero circular vitruviano como um templo coberto por um telhado cônico duplo, uma idéia que remonta, ao que tudo indica, a Bramante. Contudo esse fato não corresponde absolutamente aos dados arqueológicos, pois, em toda a Antigüidade, existiu um único templo com esse aspecto (a thólos de Képoi; cf. GROS, 1997, p. 506). Vitrúvio é constantemente acusado de ditar normas que simplificam a complexidade tipológica, principalmente no âmbito da arquitetura religiosa, mas o seu intuito é sempre o de apresentar, de maneira mais ou menos uniforme, normas para a realização de elementos que na realidade divergem entre si, embora as suas prescrições costumem ser quase uma média ponderada que uniformiza a diversidade da realidade material. Por que então ele iria se referir a uma tipologia tão exótica, apresentando-a como modelo normativo?

Neste ponto, oponho-me a uma tradição já consolidada, constituída por tradições menores divergentes apenas em detalhes, que aceita de modo unânime uma interpretação que não se sustenta no confronto com os dados arqueológicos. Nenhum dos editores mais recentes de Vitrúvio desconfia da lição transmitida a ponto de alterála, como fazem em tantos outros passos de menor importância. Torna-se necessária, pois, uma leitura coerente com a realidade material, devendo-se interpretar o texto de forma a conservar o significado esperado, mas com consciência da impossibilidade de comprovar a sua legitimidade, senão através da persuasão.

Quanto ao capitel jônico, a despeito das atuais incertezas dos especialistas, creio ser possível chegar a um resultado mais consistente. O problema não é, afinal, tão complicado, e já Salviati (1552) encontrou empiricamente a solução. A questão que se colocou então, e que parece ter se perpetuado entre os intérpretes posteriores, foi a necessidade dos três giros presentes nos capitéis jônicos conhecidos, particularmente o do Teatro de Marcelo. Através de comparações no uso da palavra tetrantes em diversos passos da obra, seguindo a regra do usus scribendi, é possível, na minha opinião, estabelecer um significado que permite executar todos os movimentos prescritos no texto sem desrespeitá-lo e desenhar uma voluta perfeitamente coerente com a documentação material. Também nesse caso, o grande empecilho para uma interpretação menos alegórica é a força de uma tradição que sempre acusou Vitrúvio de ser excessivamente breve e pouco claro, mas todas as palavras estiveram sempre no texto.

Essa espécie de inércia interpretativa fica perfeitamente clara no caso dos scamilli inpares (cf. CAMPBELL, 1980). Antes de ter sido descoberta a curvatura das horizontais do Partenon, nenhum intérprete jamais havia sequer sonhado em interpretar o texto no seu sentido literal: ou seja, que se deviam fazer acréscimos na linha horizontal do plano de apoio das colunas para que a superfície resultasse ligeiramente convexa. Somente com a comprovação científica desse tipo de curvatura, 
e de todas as outras presentes nas prescrições vitruvianas, é que o texto passou a ser interpretado coerentemente com o que está escrito. Até então, estava estabelecido que os scamilli inpares estavam associados a "pedestais" colocados sob as colunas e, ainda que tal elemento não fosse efetivamente utilizado nas construções antigas a não ser em situações muito particulares, toda a arquitetura, do Renascimento ao período neoclássico, fez intenso uso de pedestais, um fenômeno que pode ser compreendido como a materialização de uma leitura equivocada, que, de certa forma, legitimou o próprio erro, na medida em que demonstrou ser uma solução viável - nesse ponto, o processo hermenêutico se transforma em história. Se a descoberta das curvaturas possibilitou uma nova compreensão do passo, por outro lado criou novos problemas interpretativos. Inúmeras respostas têm sido dadas a essas novas questões, nenhuma plenamente satisfatória. A cada nova interpretação apresentada entra em ação, entre os estudiosos, um mecanismo de revisão, no sentido da sua superação, em um movimento da tradição exegética sem possibilidade de retorno, o que pode ser chamado de "deslocamento do horizonte hermenêutico".

Diante disso, é possível concluir que realmente a interpretação não pode se basear em um modelo estável. Os seus próprios critérios são ditados pelas circunstâncias históricas, que restringem o alcance da nossa visão a esse horizonte definido pela tradição. Mas nem por isso pode ser afirmada uma relatividade absoluta inerente a esse processo interpretativo. Algumas interpretações, como é o caso da curvatura das horizontais, são conquistas definitivamente estabelecidas. Também no âmbito da crítica do texto, cuja metodologia é mais estável, os progressos podem ser nitidamente notados. O texto de Vitrúvio é hoje muito mais legível que antes, mas o leitor tem que estar sempre atento às inúmeras questões que se colocam a cada passo da leitura, tendo sempre à mão um comentário detalhado e atualizado.

O texto da tradução da obra de Vitrúvio realizada por Lagonegro, recentemente lançada (1999), exemplifica bem essa constatação. Uma tradução em língua portuguesa da obra de Vitrúvio coloca ao tradutor problemas análogos aos que se apresentaram ao próprio autor, particularmente devido à egestas sermonis patriae, mas, em muitíssimos pontos, o texto traduzido diverge completamente da minha interpretação. Nessa tradução, que tem o grande mérito de ser a primeira completa do De architectura para o português, são cometidos alguns equívocos totalmente anacrônicos. Por um lado, modernizam-se muito os conceitos antigos com o uso de termos da prática arquitetônica contemporânea como tradução de termos vitruvianos, cujos conceitos são substancialmente diversos, de modo que Vitrúvio parece excessivamente moderno, expressando-se de uma forma absolutamente inimaginável; por outro lado, tomando como exemplo novamente os scamilli inpares, interpretam-se determinados passos tal como séculos atrás, e Vitrúvio se parece mais com Philander ou com Perrault, seus intérpretes dos séculos XVI e XVII, que com um romano do I século a. C., da época de Augusto.

A afirmação do caráter necessariamente provisório de uma interpretação não invalida absolutamente a intenção de esclarecer os pontos obscuros do texto. Entretanto, a interpretação de Vitrúvio sempre foi fortemente condicionada pelos progressos da investigação arqueológica, mas pode ser afirmado categoricamente que também a essa metodologia não se pode conferir uma validade absoluta. Em suma, as respostas às questões suscitadas pelo texto devem ser buscadas através de um processo intenso de diálogo com o próprio texto e com todo o conjunto da tradição, pois apenas o contato íntimo com a alteridade da língua de Vitrúvio e a consciência dos 
limites impostos pela nossa própria condição histórica podem nos dar alguma certeza para enfrentar a tarefa que o texto nos impõe: a exigência de ser decifrado.

O comentário exegético demonstra-se ser o melhor caminho para a reconstituição do significado dos passos obscuros, pois, para a compreensão de um texto enquanto forma, é necessária a compreensão de cada parte, de cada palavra, para depois se retornar ao todo e encontrar o sentido. Nesse ponto, fundem-se a metodologia antiga e a contemporânea: realiza-se o círculo hermenêutico. Eis aqui a resposta à interrogação inicial: é assim que Vitrúvio deve ser lido, pois, para o compreender, deve-se interpretá-lo. Permanece sempre o problema do caráter pessoal da interpretação, pois não é mais a voz do autor a voz que fala, é um outro texto, que reflete o original e reflete outras interpretações, de um modo quase caleidoscópico, mas é exatamente esse desdobramento contínuo do texto o que nos faz participar da sua história como co-autores e garante a Vitrúvio a sua eternidade.

Abstract

This work presents some considerations regarding the current stage of the reception of Vitruviu's De architectura, characterized by strong oppositions among researchers, which generally transcend the linguistic difficulties and can be explained by the development of the hermeneutic process through the centuries in which the work has been studied.

Key words: Vitruvius. De architectura. Reception. Reading.

Referências

ALARÇÃO, Jorge et al. Vitruve à Conimbriga. Conimbriga, v. 17, p. 5-14, 1978.

GADAMER, Hans-Georg. Verdade e método: traços fundamentais de uma hermenêutica filosófica. Petrópolis: Vozes, 1990. (ed. or. 1960)

GROS, Pierre (cur.). Vitruvio. De architectura. Torino: Einaudi, 1997.

GROS, Pierre (ed.). Vitruve. De l'architecture: livre IV. Paris: Les Belles Letres, 1992.

GROS, Pierre. Munus non ingratum: le traité vitruvien et la notion de service. In: Le projet de Vitruve: objet, destinataires et réception du De architectura. Actes du colloque international, Rome, 26-27 mars 1993. Rome: École Française de Rome, 1994. p. 75-90.

LAGONEGRO, Marco Aurélio (trad.). Vitrúvio. Da arquitetura. São Paulo: Hucitec, 1999.

MICHEL, Alain Rhétorique, philosophie et esthétique générale: de Ciceron à Eupalinos. Revue des études latines, v. 51, p. 302-326, 1973. 
Em Tese, Belo Horizonte, v. 10, p. 91-97, dez. 2006

SALVIATI, Giuseppe. Regola di far perfettamente col compasso la voluta et del capitello ionico et d'ogn'altra sorte per Josephe Salviati pittore ritrovata. in Vinetia: per Francesco Marcolini, 1552. 